- ACORN Australan college of | JOURNAL OF PERIOPERATIVE NURSING

Volume 33 | Issue 2

Article 1

$4-6-2020$

\title{
The Perioperative Nurse Surgical Assitant (PNSA) of the future
}

Follow this and additional works at: https://www.journal.acorn.org.au/jpn

Part of the Health Services Research Commons, Online and Distance Education Commons, Perioperative, Operating Room and Surgical Nursing Commons, and the Surgery Commons c) (7)

This work is licensed under a Creative Commons Attribution 4.0 License.

\section{Recommended Citation}

Sonneborn, Olivia (2020) "The Perioperative Nurse Surgical Assitant (PNSA) of the future," Journal of Perioperative Nursing: Vol. 33 : Iss. 2 , Article 1.

Available at: https://doi.org/10.26550/2209-1092.1080

https://www.journal.acorn.org.au/jpn/vol33/iss2/1

This Discussion paper is brought to you for free and open access by Journal of Perioperative Nursing. It has been accepted for inclusion in Journal of Perioperative Nursing by an authorized editor of Journal of Perioperative Nursing. 


\section{Author}

Olivia Sonneborn

MN

Perioperative Practices Course

Coordinator

La Trobe University

Email: o.sonneborn@latrobe.edu.au

\title{
The PNSA of the future
}

\begin{abstract}
Advanced practice nurse (APN) roles have been implemented across all areas of the Australian health service and have extended into the perioperative environment in the form of the perioperative nurse surgical assistant (PNSA) or non-medical surgical assistant (NMSA). With a growing and ageing population, Australia will see an increased demand for acute care nurses. For the PNSA role to expand to meet this demand, the role requires recognition and regulation in Australia. Education programs also need to meet the increasing demand for acute care nursing and provide quality, accessible and collaborative education programs to meet the needs of all nurses in Australia, including those in rural and remote areas.
\end{abstract}

Keywords: perioperative nurse surgical assistant (PNSA), non-medical surgical assistant (NMSA), perioperative nursing, advanced practice nurse (APN), rural nursing

\section{PNSA: the past and present}

The Australian health service is constantly evolving to meet the needs of a growing and ageing population. It is meeting this need by creating innovative roles to improve patient's access to health care. Advanced practice nurse (APN) roles have been implemented across all areas of the Australian health service and have extended into the perioperative environment mainly in the form of the perioperative nurse surgical assistant (PNSA). Despite over 20 years of research articles in Australia reporting the benefits of the PNSA role there continues to be a lack of recognition of PNSAs and limitations to the broader implementation and uptake of PNSA practice $^{2-4}$.

PNSAs, also referred to in current literature as non-medical surgeon's assistants (NMSAs), have been practicing in Australia for over 20 years 5 . PNSAs are perioperative nurses who have 'acquired the knowledge, skills and attitude necessary to competently provide extended perioperative nursing care $^{\eta(p .40)}$. The care provided by the PNSA encompasses 'holistic nursing care throughout the preoperative, intraoperative and post-operative phases of a surgical patient's journey ${ }^{\eta(p .40)}$. In Australia, the PNSA role has primarily been implemented in general, orthopaedic and neurosurgery, with growing interest in using the role in plastic surgery ${ }^{6,7}$.

The lack of recognition of the NMSA stems from an absence of regulation by governing bodies such as the Australian Health Professional Regulation Agency (AHPRA). Barriers to the broader uptake of the role are limited by the exclusion of the PNSA role from Medicare Benefits Scheme (MBS) funding for intraoperative surgical assistance. Currently MBS funding is only available to medical assistants ${ }^{5,8,9}$. Most PNSAs in Australia work within the private sector and are mentored by a surgeon who provides the financial remuneration for their specialist skills not currently covered by the MBS. However, there is a small but growing number of public sector institutions which have identified the benefits of PNSAs and are beginning to implement the NMSA role $e^{9,10}$. The majority of clinicians acting as NMSAs in Australia are nurses; however, their qualifications vary considerably and this contributes to the difficulty of categorising the role as being within 
advanced practice nursing and providing recognition and regulation for the role of PNSA in Australia 5 .

The PNSA role has gained recognition and acceptance in Australia with the establishment of the Australian Association of Nurse Surgical Assistants (AANSA) in 2011. AANSA supports the PNSA profession and provides information to the general public, surgeons and health facilities ${ }^{11}$. Both AANSA's position statement for the PNSA and the ACORN Standards state that PNSAs must be registered nurses (RNs) currently registered with Australian Health Practitioner Regulation Agency (AHPRA) and that they must hold individual public indemnity and public liability insurance ${ }^{1,11}$. The PNSA is required to have a minimum of three years perioperative experience if the nurse has a postgraduate certificate in perioperative nursing, or five years' experience without it. The PNSA must also have successfully completed or be currently enrolled in a postgraduate degree in PNSA studies at an approved university. La Trobe University is the approved university in Australia currently offering such studies with online delivery options across Australia. La Trobe also provides continuing professional development opportunities for PNSAs ${ }^{12}$.

\section{What is the future of the PNSA in Australia?}

AANSA continues to lobby the health care authorities and health departments to recognise and remunerate the PNSA role, with submissions to the MBS Review Taskforce as part of this endeavour ${ }^{11}$. The extensive and eminent research undertaken by Toni Hains and other authors regarding the PNSA (or NMSA) role in Australia continues to augment the progress towards recognition and regulation of the NMSA role ren-10,13,4. $^{3}$.

Figure 1: Comparison scenario, registered and enrolled nurses, acute sector, 2012 to 2030

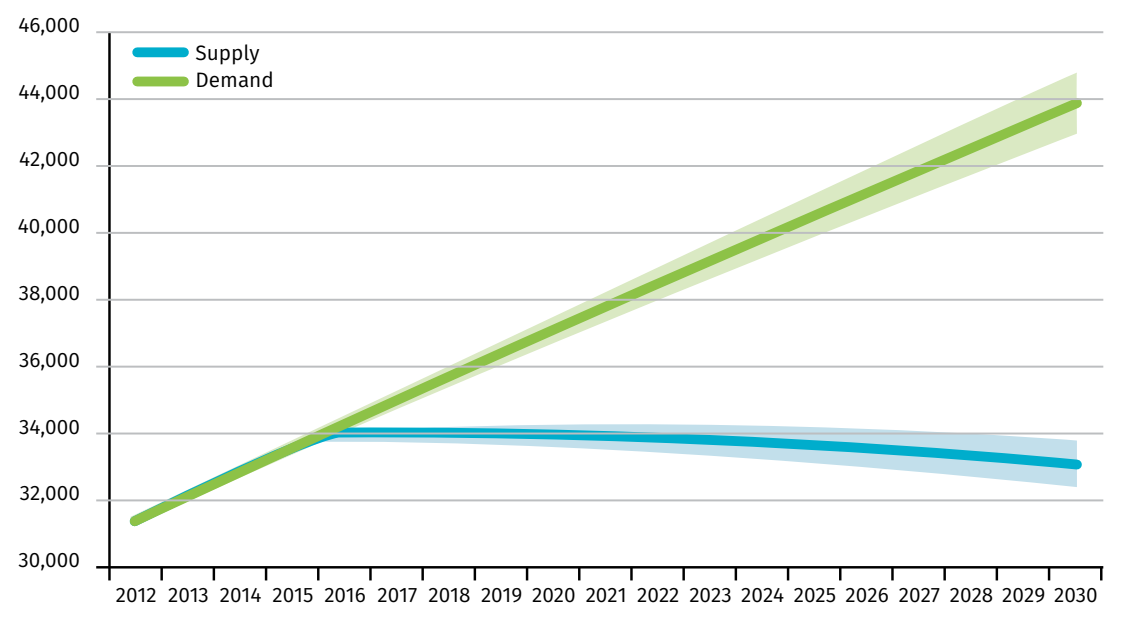

Source: Australia's Future Health Workforce - Nurses, Health Workforce Australia (2014).

There is a breadth of support for the PNSA now from surgeons who have worked with PNSAs locally and internationally and who endeavour to incorporate the quality care of the PNSA into their practice. The Royal Australasian College of Surgeons (RACS) has expressed support for the PNSA role and RACS members have expressed interest in contributing to the curriculum and training of PNSAs. This possible partnership with RACS is one that PNSA course coordinators at La Trobe University encourage and support ${ }^{6}$.

The pressure on the Australian health service from a growing and ageing population, increasing rates of chronic disease, rising costs and doctor shortages outside metropolitan areas is an area where APNs can meet essential needs for quality patient care and service delivery ${ }^{8,15,16}$. Shortages of doctors in rural and remote areas mean that RNs often act as doctor substitutes, requiring $\mathrm{RNs}$ to be multiskilled and to practice at an advanced level; this in turn is likely to lead to increased demand for the PNSA role ${ }^{14,16}$.
ACORN guidelines concede that perioperative nurses may be asked to undertake the role of surgical assistant as a substitute for unavailable doctors even when nurses have not embarked on further postgraduate studies or undertaken specific training ${ }^{1,3}$. The PNSA role is an extended role and one that rural and remote nurses often report feeling 'unprepared for' yet must still perform ${ }^{16}$. Accessible, quality education for rural and remote perioperative nurses must continue to be a priority and a focus for growth?

The Australian health service is predicted to see a shortfall of acute care nurses, including in the perioperative sector, with a need for 41000 more acute care nurses by $2030^{17}$. The number of PNSAs or NMSAs currently in Australia is not known accurately, although AANSA now has 100 active members (not all currently practicing PNSAs) ${ }^{18-20}$. Increased demand for acute care nurses and nurses to substitute for doctors' roles will require increased numbers of endorsed PNSAs in coming years. 
Tertiary institutions such as La Trobe University are in a position to provide increased flexible and accessible PNSA specialist education aimed at nurses, especially nurses in rural and remote regions. PNSA endorsement is not the sole motivator for RNs undertaking specialist postgraduate PNSA studies - many surgeons recommend undertaking further education to expand clinical practice, provide quality surgical assistance and increase personal and job satisfaction $n^{3,13,14}$. Hospital administrators also focus increasingly on service models that deliver holistic, higher quality, coordinated care at a lower cost ${ }^{21}$ with the PNSA role shown to have benefits including reduced costs, improved leadership and mentoring, and reduction in operating theatre cancellations and delays ${ }^{7,10}$. The NMSA role can also prove to be costeffective by decreasing preparation time for surgery and shortening actual operation time?. PNSAs are valued by other perioperative nurses due to a focus on improved worklife balance and working conditions, mentoring and leadership; surgeons also acknowledge their contribution to quality of care and efficiency 3,10,22,23.

There is robust support for the recognition and regulation of the PNSA role in Australia. Further developments and extension of the role are required for the PNSA role to contribute to Australian health services in the long-term. Expansion of theoretical and practical education are also necessary to support the specialist, quality care required from the PNSA in the future.

\section{Disclosure}

The author is the postgraduate course coordinator for the perioperative practices stream in the Masters of Nursing at La Trobe University.

\section{Reference List}

1. Australian College of Perioperative Nurses Ltd (ACORN). Standards for Perioperative Nursing in Australia $15^{\text {th }}$ edition. Adelaide, South Australia: ACORN; 2018.

2. Riley R, Peters G. The current scope and future direction of perioperative nursing practice in Victoria, Australia. J Adv Nurs 2000;32(3):544-553.

3. Hains T, Turner C, Haakan S. Knowledge and perceptions of the NMSA role in Australia: A perioperative staff survey. JPN 2017;30(3):3945.

4. Duff, J. See one, do one, teach one: Advanced perioperative nursing practice in Australia. JPN. 2019;32(4):3-4.

5. Hains T, Turner C, Haakan S. The nonmedical surgical assistant in Australia: Who should contribute to governance? Aust J Adv Nurs 2020;35(2):51-57.

6. Hains T, Turner C, Haakan S. Task transfer: A survey of Australian surgeons on the role of the non-medical surgical assistant. JPN 2018;31(1):11-17.

7. Hains T, Turner C, Haakan S. Practice audit of the role of the non-medical surgical assistant in Australia, an online survey. Int J Nurs Pract 2016;22:546-555.

8. Hains T, Rowell D, Strand H. Effectiveness of the non-medical surgical assistant measured by patient outcome assessment. Int J Nurs Pract 2020:2-8.

9. Yang $L$, Hains T. The plight of the perioperative nurse practitioner in Australia. Aust Nurs Midwifery J 2017;10:36-37.

10. Smith C, Hains T, Mannion N. An opportunity taken: Sunshine Coast University Private Hospital's perioperative nurse surgeon's assistant experience. JPN 2016;29(3):23-28.

11. Australian Association of Nurse Surgical Assistants (AANSA). Position description - perioperative nurse surgical assistant. Brisbane: AANSA; 2020 [cited 2020 March 12] Available from www.aansa.org.au.

12. Latrobe University. Short courses for nurses and midwives [Internet]. Melbourne: Latrobe University; 2020 [cited 2020 March 12]. Available from www.latrobe.edu.au/__data/ assets/pdf_file/0011/891623/2020-NursingContinuing-Professional-DevelopmentShort-Courses.pdf.

13. Hains T, Strand H, Turner C. An international appraisal of the role of the non-medical surgical assistant. JPN 2017;30(2):37-42.

14. Lynn A, Brownie S. The perioperative nurse surgeon's assistant: Issues and challenges associated with this emerging advance practice nursing role in Australia. Collegian 2015;22:109-115.
15. Bryan E. Perioperative nurse surgeon's assistant in day surgery an emerging role within Australia's health system. Ambul Surg 2010;16(2):25-27.

16. Muirhead S, Birks M. Roles of rural and remote registered nurses in Australia: An integrative review. Aust J Adv Nurs 2019;37(1):21-33.

17. Health Workforce Australia (HWA). Australia's future health workforce: Nurses detailed report. [Internet]. Canberra: HWA; 2014 [cited 2020 March 12]. Available from: www1.health.gov.au/internet/main/ publishing.nsf/Content/34AA7E6FDB8C16A ACA257D9500112F25/\$File/AFHW\%20-\%20 Nurses\%20detailed\%20report.pdf.

18. Hall S, Quick J, Hall A, Jones A. Surgical assistance: Who can help? [Internet]. London: The Royal College of Surgeons of England; 2014 [cited 2020 March 12]. Available from: publishing.rcseng.ac.uk/doi/ pdfplus/10.1308/rcsbull.2014.96.7.244.

19. Quick J, Hall S, Jones A. The surgical care practitioner role problems and possible solutions from nurses in the UK offered to RNFSA colleagues in New Zealand. The Dissector 2014;42(1):32-34.

20. Quick J. The role of the surgical care practitioner within the surgical team. $\mathrm{Br}$ J Nurs 2013;22(13):759-765.

21. Desebbe O, Lanz T, Kain Z, Cannesson M. The perioperative surgical home: An innovative, patient centred, cost-effective perioperative care model. Anaesth Critic Car Pain Med 2016;35:59-66.

22. Van Der Weyden M. Task transfer: Another pressure for evolution of the medical profession. Med J Aust 2006;185(1):29-31.

23. Brand S, Thompson Coon J, Fleming L, Carroll L, Bethel A, Wyatt K. Wholesystem approaches to improving health and wellbeing of healthcare workers: A systematic review. Plos One 2017:1-26. 